ЭТНИЧЕСКАЯ ИДЕНТИЧНОСТЬ ПОДРОСТКОВ-НЕНЦЕВ, ПРЕДСТАВИТЕЛЕЙ КОРЕННЫХ НАРОДОВ КРАЙНЕГО СЕВЕРА РОССИИ

\author{
Н.С. Флотский, Н.Ю. Флотская, С.Ю. Буланова, М.А. Пономарева \\ ФГАОУ ВО «Северный (Арктический) федеральный университет \\ имени М.В. Ломоносова», Архангельск, Россия (163002. 2. Архангельск, набережная \\ Северной Двины, д. 17), nikolay.flotskiy@gmail.com
}

В статье рассматривается проблема этнической идентичности подростков-ненцев, представителей коренных народов Крайнего Севера России. Представлено исследование специфики этнической идентичности подростков-ненцев в сравнении с их сверстниками русской национальности. Респондентами являлись подростки 12-15 лет мужского и женского пола русской национальности, проживающие на территории Архангельской области, и их сверстники-ненцы, проживающие на территории Ненецкого автономного округа. В исследовании анализировались показатели этнической идентичности (этнонигилизм, этническая индифферентность, позитивная этническая идентичность, этноэгоизм, этноизоляционизм и этнофанатизм), входящие в психодиагностическую методику Г.У.Солдатовой, С.В.Рыжовой «Типы этнической идентичности». В ходе изучения этнической идентичности мальчиков и девочек подросткового возраста ненецкой национальности было установлено, что существует специфика этнической идентичности подростков-ненцев в сравнении с их сверстниками русской национальности. Наибольшие различия в показателях этнической идентичности между представителями ненецкой и русской национальности были выявлены у респондентов мужского пола. У мальчиков ненецкой национальности в сравнении с их русскими сверстниками отличаются показатели этнической индифферентности, позитивной этнической идентичности и этнофанатизма. У девочек ненецкой национальности в сравнении с их русскими сверстницами отличается только один показатель - позитивная этническая идентичность.

Ключевые слова: этническая идентичность, подростковый возраст, подростки ненецкой национальности, подростки русской национальности.

\title{
ETHNIC IDENTITY OF NENETS TEENAGERS - REPRESENTATIVES OF INDIGENOUS PEOPLES OF THE FAR NORTH OF RUSSIA
}

Flotskiy N.S., Flotskaya N.Y., Bulanova S.Y., Ponomareva M.A.

Northern (Arctic) Federal University named after M.V. Lomonosov, Arkhangelsk, Russia (163002, Arkhangelsk, Severnaya Dvina Emb. 17) nikolay.flotskiy@gmail.com

The article describes ethnic identity of Nenets teenagers - representatives of the indigenous peoples of the far north of Russia. The study of ethnic identity special features with Nenets teenagers comparing with their Russian peers is presented. The respondents were adolescents 12-15 years old, male and female, of Russian nationality, living in Arkhangelsk region and their peers of Nenets nationality, living in the Nenets Autonomous District. The study analyzes the characteristics of ethnic identity (ethnic nihilism, ethnic indifference, positive ethnic identity, ethnic selfishness, ethnic isolationism and ethnic fanaticism) included in psycho-diagnostic 
method of G.U. Soldatova, S.V. Ryzhova "Ethnic Identity Types". During the study of ethnic identity with Nenets teenagers (both boys and girls) we have found out that there is a difference between ethnic identity with Nenets adolescents and their Russian peers. The greatest differences of ethnic identity characteristics between Nenets and Russian teenagers were revealed in male respondents. Nenets boys comparing with Russian peers differ in characteristics of national indifference, positive ethnic identity and ethnic fanaticism. Nenets girls comparing with Russian peers differ only in one characteristic - positive ethnic identity.

Kew words: ethnic identity, adolescence, Nenets teenagers, Russian teenagers.

\section{Исследование выполнено при поддержке проекта № 07-2018-02а «Изучение личности и этнической идентичности у подростков - ненцев, проживающих на территории}

\section{Архангельской области»}

Современная отечественная психологическая наука все чаще обращается к проблемам психического развития в подростковом возрасте. На наш взгляд, это является вполне обоснованным, т.к. данный период особенно значим для становления личности человека. Известно, что в данном возрасте осуществляется переход от детства к зрелости в социальном, эмоциональном и когнитивном аспектах. Такой переход сопровождается формированием у подростка чувства взрослости, отражающего изменение системы отношений к себе, людям, миру и определяет содержание его социальной активности, особенности внутренней жизни. Приобретение этих признаков проявляется в самоутверждении и демонстрации собственной позиции родителям и сверстникам. Характеристики подросткового возраста включают целый ряд компонентов: кризисность развития, специфическую социальную активность, изменение системы ценностей, формирование самосознания. Все это определяет новую жизненную позицию подростка по отношению как к окружающим, так и к себе. В подростковом возрасте отмечается особая восприимчивость к усвоению ценностей, норм и образцов поведения, что связано с процессом становления идентичности [5]. При этом подростковый период значим для развития личностной идентичности, гендерной идентичности, этнической и других видов идентичности $[1,3]$.

Учитывая, что одной из особенностей современного социума является поликультурность и многоконфессиональность, на первый план выходят проблемы обеспечения взаимопонимания, позитивного и толерантного отношения членов общества друг к другу. Исторически сложилось так, что в России указанные проблемы всегда существовали и, как правило, находили свое решение [4]. Сфера межэтнического взаимодействия особенно уязвима с точки зрения возникновения негативных стереотипов, предрассудков, которые могут приводить к межэтническим конфликтам. Для профилактики 
и предотвращения подобных проблем необходимы специальные исследования процесса становления этнической идентичности у представителей разных национальностей и народностей. Так, на приарктических территориях Европейского Севера России проживают представители коренного малочисленного народа - ненцы. Эта народность отличается самобытным жизненным укладом и своеобразной культурой, что неизбежно отражается на их самосознании и идентичности.

Интенсивные социальные изменения в сфере этнических процессов малых и малочисленных этносов России, начавшийся в начале XXI века, государственные программы, направленные на сохранение малочисленных народов, их языка, культуры оказали большое влияние на развитие идентичности представителей этих этносов, в том числе и представителей коренных народов Крайнего Севера. В современном поликультурном российском обществе большую актуальность приобретает сохранение этнокультурной преемственности и формирование современного исторического сознания, интеграция этнической и гражданской идентичности у коренных малочисленных народов Крайнего Севера и Арктики. Концепция национальной образовательной политики Российской Федерации нацеливает работу образовательных учреждений всех уровней на создание условий, обеспечивающих формирование этнокультурной идентичности обучающихся.

В связи с этим, интерес представляет исследование специфики этнической идентичности подростков-ненцев в сравнении с их сверстниками русской национальности. Целью нашей работы являлось изучение этнической идентичности мальчиков и девочек подросткового возраста ненецкой национальности.

Эмпирическое исследование проводилось с апреля по июнь 2018 года на территории Ненецкого автономного округа Архангельской области. В качестве респондентов выступили 47 подростков ненецкой национальности (26 мальчиков и 21 девочка) и 61 подросток русской национальности (32 мальчика и 29 девочек) в возрасте 12-15 лет. В исследовании была использована психодиагностическая методика Г.У. Солдатовой, С.В. Рыжовой «Типы этнической идентичности» [2]. Методика включает 6 шкал: этнонигилизм (отрицание собственной этнической идентичности), этническая индифферентность (неопределенность собственной этнической идентичности и безразличие к этнической принадлежности других), позитивная этническая идентичность (уважительное отношение к любой этнической принадлежности), этноэгоизм (подчеркивание преимущества своей этнической группы), этноизоляционизм (убежденность в превосходстве своей этнической группы), этнофанатизм (готовность к агрессивным действиям в интересах своей этнической группы). 
Анализ полученных результатов свидетельствует о наличии особенностей в характеристиках этнической идентичности у подростков ненецкой национальности в сравнении с их русскими сверстниками. Данные особенности в большей степени выражены у подростков-мальчиков. Однако у мальчиков и девочек той и другой национальности существуют общие тенденции в характеристиках этнической идентичности. Так, наибольшую степень выраженности у мальчиков и девочек той и другой национальности в подростковом возрасте имеют такие показатели, как позитивная этническая идентичность и этническая индифферентность. В то время, как наименьшую степень выраженности имеет показатель этнонигилизма.

При сравнении характеристик этнической идентичности у мальчиков и девочек ненецкой и русской национальности можно отметить, что показатели этнонигилизма, этнической индифферентности и позитивной этнической идентичности чуть выше у подростков русской национальности, а показатели этноэгоизма, этноизоляционизма и этнофанатизма - чуть выше у подростков ненецкой национальности. Причем данные отличия имеют место и у мальчиков, и у девочек (рис. 1, рис. 2). Предполагаем, что такое сходство в характеристиках этнической идентичности у мальчиков и девочек может объясняться влиянием общей социокультурной и образовательной среды, в которой они находятся.

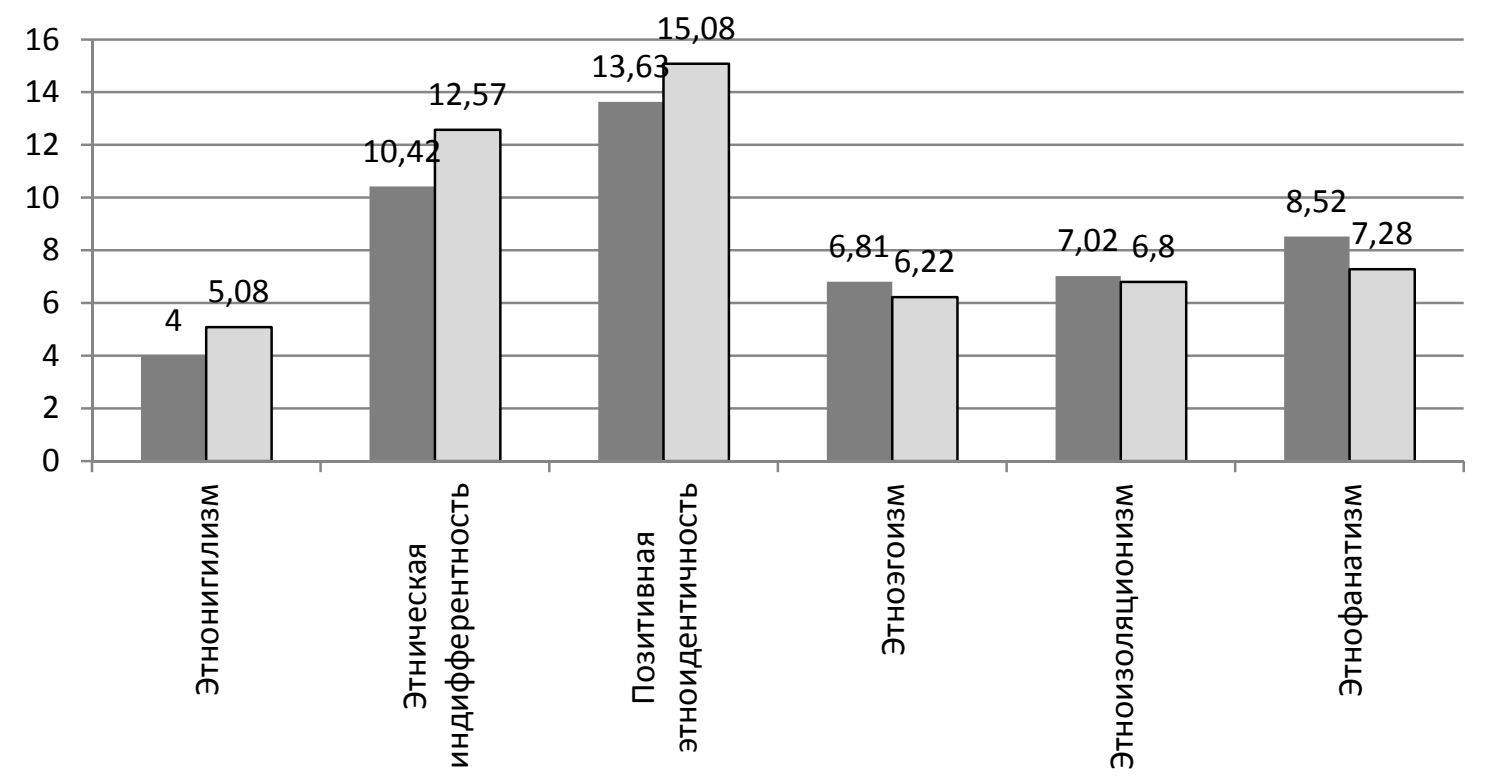

— Мальчики ненецкой национальности

$\square$ Мальчики русской национальности

Рис. 1. Этническая идентичность мальчиков подросткового возраста ненецкой русской национальности 


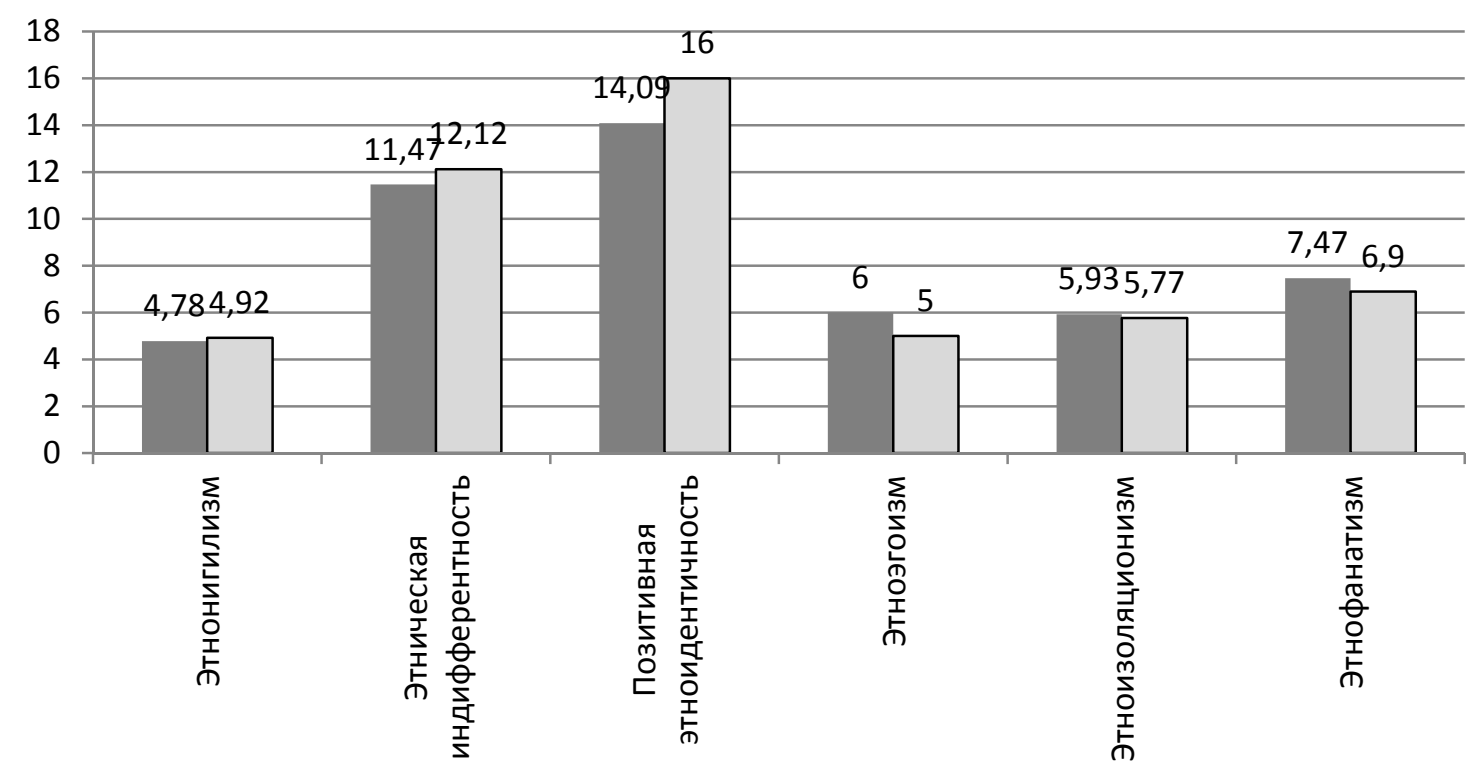

— Девочки ненецкой национальности

$\square$ Девочки русской национальности

Рис. 2. Этническая идентичность девочек подросткового возраста ненеикой русской национальности

Анализируя результаты, полученные у респондентов мужского пола, можно отметить, что у мальчиков ненецкой национальности в сравнении с их русскими сверстниками существенно ниже показатели этнической индифферентности $(p<0,001)$, позитивной этнической идентичности $(\mathrm{p}<0,01)$ и существенно выше показатель этнофанатизма $(\mathrm{p}<0,05)$. То есть, у мальчиков-ненцев более выражена готовность к агрессивным действиям в интересах своей этнической группы, в то же время, менее выражены неопределенность собственной этнической идентичности и безразличие к этнической принадлежности других, а также уважительное отношение к любой этнической принадлежности. Предполагаем, что в подростковом возрасте мальчики-ненцы острее чувствуют собственную национальную принадлежность, стремятся ее подчеркнуть, испытывают потребность находиться внутри своей этнической группы и защищать ее интересы. Все это обусловливает их гораздо меньшее внимание к другим этносам и менее дружелюбное к ним отношение.

Анализируя результаты, полученные у респондентов женского пола, подчеркнем, что у девочек ненецкой национальности в сравнении с их русскими сверстницами существенно ниже только один показатель - позитивная этническая идентичность ( $<00,01)$. При этом сам по себе он несколько выше, чем у мальчиков - ненцев. Схожесть показателей этнической идентичности у девочек подросткового возраста ненецкой и русской национальности может, на наш взгляд, объясняться тем, что для девочек - ненок не так значимы преимущества своей этнической группы, они не испытывают необходимости чувствовать ее превосходство. 
Поскольку девочки в целом менее склонны к агрессии, то девочки-ненки не демонстрируют готовность отстаивать интересы своей этнической группы в агрессивных формах.

Таким образом, наибольшие различия в показателях этнической идентичности между представителями ненецкой и русской национальности были выявлены у респондентов мужского пола. У мальчиков-ненцев менее выражены неопределенность собственной этнической идентичности и безразличие к этнической принадлежности других, а также уважительное отношение к любой этнической принадлежности, при этом у мальчиковненцев более выражена готовность к агрессивным действиям в интересах своей этнической группы в сравнении с их русскими сверстниками. Сравнительно меньшие различия в показателях этнической идентичности между представителями ненецкой и русской национальности были выявлены у респондентов женского пола. Девочки-ненки в меньшей степени демонстрируют уважительное отношение к представителям любой этнической принадлежности, чем их русские сверстницы. Итак, в ходе изучения этнической идентичности мальчиков и девочек подросткового возраста ненецкой национальности было установлено, что существует специфика этнической идентичности подростков-ненцев в сравнении с их сверстниками русской национальности.

\section{Список литературы}

1. Зверева М.А. Психологические особенности взаимосвязи этнических автостереотипов и этнической идентичности в подростковом возрасте // Психолого-педагогические исследования. 2010. № 3. - С. 1-11.

2. Солдатова Г.У. Диагностика типов этнической идентичности / Психология общения, под общ. ред. А. А. Бодалева. М.: Когито-центр. 2011 - 511 с.

3. Тихонова И.В., Куфтяк Е.В. Этническая идентичность и ее уровни как критерии психического здоровья детей и подростков. Кострома: КГУ им. Н.А. Некрасова, 2010.

4. Чеботарёва Е.Ю. Этническая идентичность молодёжи в полиэтнической среде // Вестник Российского университета дружбы народов. 2012. №1. С. 22-28.

5. Flotskaya N., Bulanova S., Ponomareva M., Flotskiy N., Konopleva T. Gender Identity Development among Teenagers Living in the Subarctic Region of Russia // Behav. Sci. 2018, $8(10), 90$. 